\title{
Information processing and management using citation network and keyword analysis to perform a systematic literature review on Green Supply Chain Management
}

\author{
Fernanda Strozzi $^{*}$, Claudia Colicchia ${ }^{1}$ \\ Department of Integrated Business Management, Carlo Cattaneo University - LIUC, Castellanza, Italy, ${ }^{1}$ Hull University Business School, \\ Logistics Institute, University of Hull, Hull, UK
}

\begin{abstract}
The field of Green Supply Chain Management (GSCM) has recently gained considerable attention from both academics and practitioners. This has caused an exponential growth in the number of publications related to different aspects of sustainability in the supply chain. This study aims to show information processing and management techniques, to reveal the evolution of a field over time and identify directions for future research. In particular, this paper is intended to provide a systematic literature review using citation network and the analysis of words in titles and author keyword through burst detection algorithm. Crossing the results of the citation network and burst detection algorithm it was possible to monitor the evolution of the sustainability drivers and to identify the necessity of new key performance indicators of sustainability, able to integrate the economic, environmental and social dimensions, internally within the organization, and externally among the supply chain partners. The contribution of this study lies in the adoption of a blind methodology to analyze theory development which have not been yet applied to the field of GSCM but proved to be useful and promising.
\end{abstract}

Keywords: Burst detection algorithm, citation network analysis, Green Supply Chain Management, main path

\section{INTRODUCTION}

The cross-disciplinary field of Green Supply Chain Management (GSCM) has recently become more and more of a concern among both academics and practitioners. ${ }^{[1]}$ Hassini et al. ${ }^{[2]}$ defined GSCM as the management of supply chain operations, resources, information, and funds in order to maximize the supply chain profitability while at the same time minimizing the environmental impacts and maximizing the social well-being.

*Address for correspondence:

E-mail: fstrozzi@liuc.it

\begin{tabular}{|l|l|}
\hline \multicolumn{2}{|c|}{ Access this article online } \\
\hline Quick Response Code: & \\
\hline & Website: \\
\hline & www.jscires.org \\
& \\
\hline
\end{tabular}

The growing interest of academy in GSCM is shown by the number of literature reviews on this subject recently published. ${ }^{[3-5]}$ The emphasis of these studies is on an extensive review of the relevant literature or on the analysis of a specific aspect within the broader area of GSCM, for example, modeling approaches for sustainable supply chain management, the integration of social aspects into the organizational strategies of companies.

This paper aims to understand if a systematic review of the literature based on methodologies of information

This is an open access article distributed under the terms of the Creative Commons Attribution-NonCommercial-ShareAlike 3.0 License, which allows others to remix, tweak, and build upon the work non-commercially, as long as the author is credited and the new creations are licensed under the identical terms.

For reprints contact: reprints@medknow.com

How to cite this article: Strozzi F, Colicchia C. Information processing and management using citation network and keyword analysis to perform a systematic literature review on Green Supply Chain Management. J Sci Res 2015;4:195-205. 
processing and management can improve our understanding of GSCM. The aim is to identify the evolution of the GSCM literature from 1992 to 2013 using citation network analysis (CNA) together with title and keyword analysis that, to the best of authors' knowledge, have not been yet applied to this field. The value of systematic reviews in the area of supply chain management based on a robust, auditable methodology is recognized as essential to support theory development in the subject area. ${ }^{[6]}$

CNA is a collection of tools, such as main path (MP) and burst detection that help to detect the dynamics of a field.

The representation of a field of research as a network and its analysis using citations is not new. Citation network measures were analyzed by Otte and Rousseau ${ }^{[]]}$and an extension of the concept of citation to detect important works, based on Google ranking method, was proposed by $\mathrm{Ma}$ et al. ${ }^{\left[{ }^{[8]}\right.}$ Thelwall et al. ${ }^{[9]}$ applied CNA to water resource management performing a bibliographic research on Google. Kajikawa et al. ${ }^{[10]}$ Nakamura, ${ }^{[11]}$ and Colicchia and Strozzi ${ }^{[12]}$ investigated the development of sustainability science, supply chain research and supply chain risk management, respectively, analyzing citation data collected from the databases compiled by the Institute for Scientific Information (ISI) through the web of science. Different techniques are then available to conduct an analysis of the citation network. Thelwall et al. ${ }^{[0]}$ measured the frequency of occurrence of nouns or sentences, Kajikawa et al. ${ }^{[10]}$ and Nakamura ${ }^{[11]}$ analyzed the clusters, whereas Colicchia and Strozzi ${ }^{[12]}$ studied the $\mathrm{MP}^{[13]}$ using the citation weights associated to the links, i.e., the citations between papers. Strozzi and Colicchia ${ }^{[14]}$ applied Citation Network Analyzer software to Google Scholar database to review the robustness measures in supply chains and Strozzi et al. ${ }^{[15]}$ reviewed the literature on environmental indicators for supply chains using a systematic literature network analysis (SLNA) methodology which again represents the literature as a citation network.

The methodology of this work consists in applied SLNA twice: To literature reviews and to papers separately. This allowed to quickly compare the results of this literature review with the existing ones and to analyze the advances in the theory in a systematic way.

The remainder of this paper is organized as follows. After the description of the adopted research methodology (Section 2), the results of a systematic analysis of the considered citation network are presented in Section 3. Directions for further research are discussed in Section 4, while in Section 5 the pros and cons of the adopted methodology are presented. In the final section, research limitations are identified, and conclusions are drawn.

\section{METHODOLOGY}

A two-step approach was used to analyze the literature on GSCM [Figure 1]. In the first instance, a systematic analysis of previous reviews of GSCM literature was performed to discover the mostly investigated topics within the field and to highlight the distinctive features of this review with respect to the already existing ones. An analysis of peer-reviewed articles different from literature reviews follows with the aim of identifying trends and evolution in the field of GSCM. A number of future research directions will be then identified and discussed.

In line with existing literature review approaches books, book reviews, editorials, and brief commentaries were not included in the analysis. Since the scope of this paper is not limited to a particular aspect of the field under study, the search string used to collect data was "GSCM". The search was conducted in the online journal database Thomson Reuters Web of Science. The rationale for this choice is that it provides researchers, administrators, faculty, and students with quick, powerful access to the world's leading citation databases. Authoritative, multidisciplinary content covers over 12,000 of the highest impact journals worldwide including Open Access journals and over 150,000 conference proceedings (http://thomsonreuters.com/ web-of-science-core-collection/). By restricting the search to peer-reviewed journals, it was deemed that the search results could be enhanced due to the rigorous

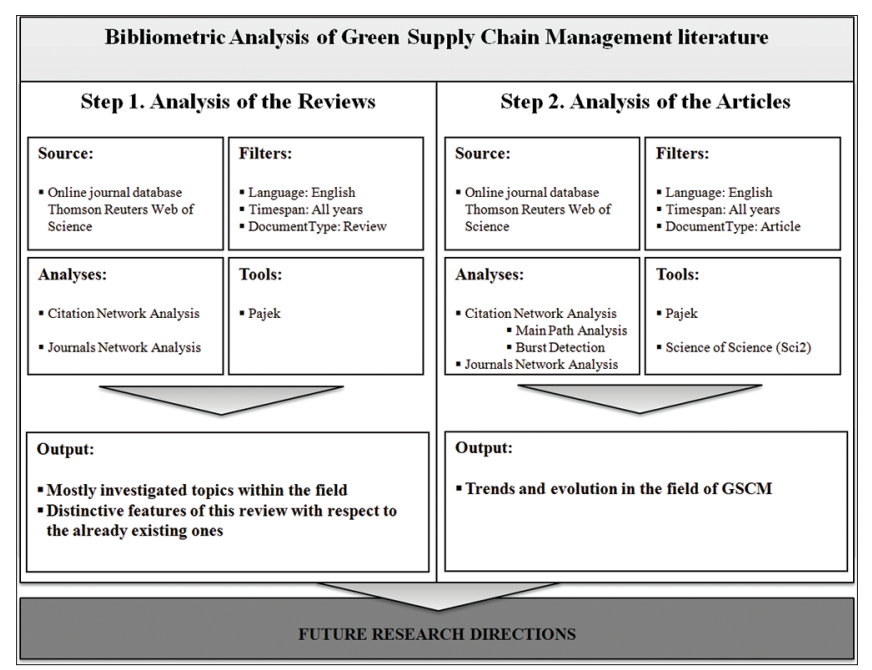

Figure 1: Research methodology 
review process to which the articles are submitted prior to publication. ${ }^{[12,16]}$

To analyze the data and extract information we have applied the citation network methodologies that can help to visualize and to extract information from the papers based on their citations.

Different software packages were used to perform such analysis: Pajek ${ }^{[17]}$ and Science of Science $\left(\mathrm{Sci}^{2}\right)$ (http://cns.iu.indiana.edu). Pajek is a software for Windows (http://pajek.imfm.si) (http://mrvar.fdv.uni-lj.si/pajek/) for the analysis and the visualization of large networks (having some thousands or even millions of vertices). $\mathrm{Sci}^{2}$ Tool is a modular toolset specifically designed for the study of science and it supports the temporal, geospatial, topical, and network analysis and visualization of datasets.

The systematic analysis of the selected reviews and of the selected articles included the following steps: First an analysis of the citation network was performed, where the nodes of the network are the reviews/articles and the links among them are the citations; second, an analysis of the journals network was performed, where the nodes of the network are the journals in which reviews/articles have been published and the links among them represent the number of times the reviews/articles included in the network and published in one journal cited the reviews/articles included in the network and published in the other journal. From these representations, it is possible to easily identify clusters of reviews/articles and relationships among them. The underpinning assumption of the CNA is that fields of research are not just formless sets of articles in terms of citations. It considers a citation network as a system of channels which transform scientific knowledge or information, assuming that researchers in the same field tend to cite each other in order to position their work in the field based on previous knowledge..$^{[13]}$

The citation network of reviews is composed of 16 nodes. All these reviews were read in their entirety by the authors to capture the analyzed issues. The citation network of articles is constituted of 384 nodes. Taking into account the aim of the present paper, i.e., to identify the evolution of the GSCM literature, the MP methodology and the Burst detection algorithm were applied, and the results arising from their application were compared.

\section{Main Path Analysis}

The MP methodology was specifically designed to extract few papers that are able to describe the evolution of the field. ${ }^{[13]}$ This algorithm does not necessarily find the most original or the best papers but the path more often walked in the full network to reach the newest papers starting from the most ancient ones. By analyzing the chronological network of citations among the selected papers, it is possible to show the dynamic behavior of the field under study, making its development over time visible. In fact, the MP highlights the articles that build on prior articles but continue to act as an authority in reference to later works. ${ }^{[18]}$ We refer the interested reader to Colicchia and Strozzi ${ }^{[12]}$ for a description of the steps to perform MP analysis.

\section{Burst Detection}

The burst detection algorithm allows identifying the increase in the frequency of the use of some words in original keywords or title. ${ }^{[19]}$ The words in original keywords or title are deemed to provide a reasonably detailed picture of an article's focus and the analysis of their evolution over time has proved to be a helpful method in identifying research trends. ${ }^{[20]}$

Kleinberg's burst detection algorithm ${ }^{[19]}$ identifies sudden increases (o state transitions) in the words frequencies. State transitions correspond to points in time around which the frequency of the words changes significantly. The algorithm generates a list of the word bursts, ranked according to the burst weight, together with the intervals of time in which these bursts occurred. The burst weight represents how great the change in the word frequency is. We have chosen to detect the bursts in original keywords (or author keywords) and words in titles. With this procedure, it is possible to identify relevant topics, terms, or concepts that have increased in use were more active for a period of time and then vanished. Because the algorithm itself is case-sensitive, it is advisable to normalize the target data before applying the algorithm of bursting. The process of normalization implemented in $\mathrm{Sci}^{2}$ separates the text into tokens word, normalizes them in lowercase, it removes the $s$ at the end of words, remove the dots from acronyms, delete the stop words, and applies the English Snowball stemmer (http://snowball.tartarus.org/algorithms/ english/stemmer.html).

In the online Thomson Reuters Web of Science database two kinds of keywords are listed: The original keywords, i.e., terms that the authors feel best represent the content of the papers and ISI keywords (or keywords plus); the ISI keywords are words or phrases that frequently appear in the titles of an article's references, but do not appear in 
the title of the article itself. In this work, we have applied the burst detection algorithm only to original keywords and titles words. The reason for this selection is that original keywords and titles words are chosen from the authors while ISI keywords by the editors and they take into account the references and thus the past trends of the literature.

\section{RESULTS AND DISCUSSION}

\section{Information Extraction from Reviews Citation Network}

The citation network of the reviews is shown in Figure 2. It has one connected component and 5 isolated nodes. The links among articles represent the flow of knowledge. The arrow from node $\mathrm{A}$ to node $\mathrm{B}$ means that article $\mathrm{B}$ cites article $\mathrm{A}$ since it needs the information of article $\mathrm{A}$ to develop its founding.

The seeds of the connected component of the citation network from which the other reviews seem to have origin are Corbett and Klassen, ${ }^{[21]}$ Srivastava, ${ }^{[5]}$ and Seuring and Muller. ${ }^{[22]}$ They analyzed GSCM from the point of view of the quality management, the reverse logistics, the triggers of GSCM and they underlined the necessity to integrate the social aspects. The appearance of many reviews in few years is a sign of the high activity in the field and a mark of the necessity to identify research trends on this subject. More recent reviews point out how social aspects are still not enough integrated ${ }^{[3]}$ and Hoejmose and Adrien-Kirby, ${ }^{[23]}$ Ashby et al. ${ }^{[4]}$ and Jabbour, 2013 ${ }^{[24]}$ tried to review the few advances in the social dimension of GSCM. Other reviews are more concentrated on the spread of GSCM practice along the chain due to the stakeholder influence. ${ }^{[25]}$

In Figure 3 the related journals network is shown. In this case, the nodes are the journals on which the reviews have been published and the link between A and B characterized

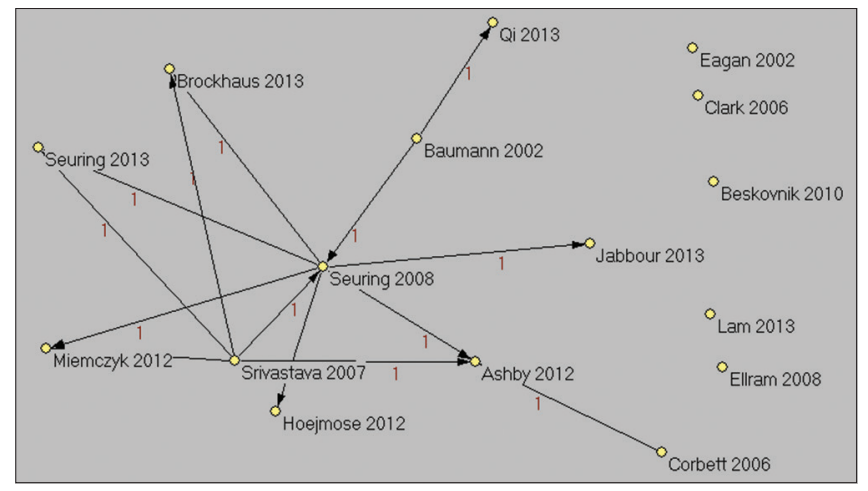

Figure 2: Citation network of reviews on Green Supply Chain Management by a weight $n$ means that the reviews included in the network and published in B have cited the ones of times.

The isolated nodes in the citation network correspond to the isolated nodes in the journals network and this means that they belong to journals with different aims and scopes [Figures 2 and 3]: Beškovnik Band Jakomin ${ }^{[26]}$ was published in Promet-Traffic and Transportation; Eagan and Kaiser ${ }^{[2]}$ in Environmental Health Perspective; Lam and $\mathrm{Gu}^{[28]}$ in International Journal of Shipping and Transport Logistics; and Clark and Snedeker ${ }^{[29]}$ in Journal of Toxicology and Environmental Health. An exception of this is represented by Ellram et al. ${ }^{[30]}$ The review has been published in the Journal of Cleaner Production, which is really focused on GSCM, but it has not been cited by the other reviews of the network. This may be due to the fact that it analyses a very specific topic, i.e., the impact of new product development on the triple bottom line and the need for further research on the relationship between new product development and the environmental impact of products.

Our literature review on GSCM is different from the ones found in Thomson Reuters Web of Science and mentioned in the reviews network mainly because it represents the field as a citation network and it tries to detect the evolution of the field and the research trends using MP and burst detection algorithm. The advantages of these methods are that they are nearly blind, and thus they allow analyzing a large amount of papers rather quickly. Since it is the first attempt using these methodologies to study GSCM literature, this article is also a way to understand if these techniques can be useful or deviant.

\section{Information Extraction from Papers Citation Network}

Many tools of complex network analysis implemented to study citation networks can be applied only if the network

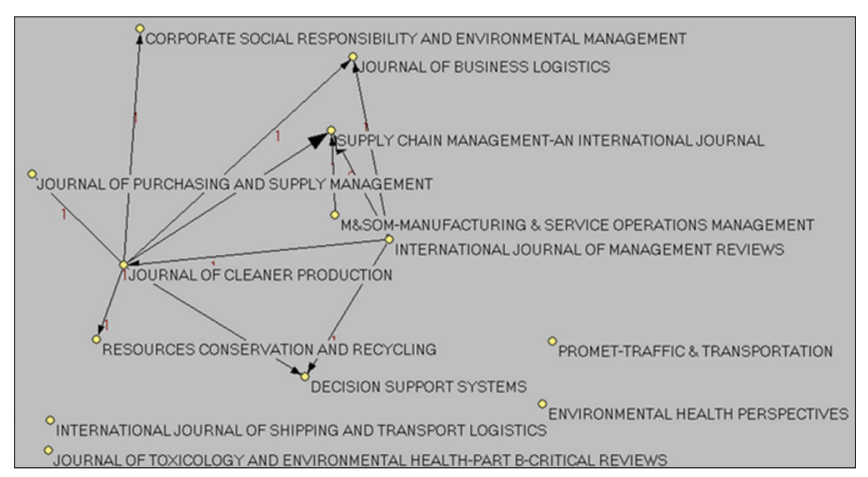

Figure 3: Journals network of reviews on Green Supply Chain Management 
is connected. The citation network of articles (composed of 384 nodes) includes a main connected component of 337 papers [Figure 4] which contains almost all of the articles.

To achieve the goal of this paper, we applied the methodologies of CNA to the main connected component. MP it is a tool of the CNA that allows simplifying a connected citation network selecting the papers that have been more important for the development of the field and then. They are deemed able to detect the evolution of the field under study.

\section{The evolution of the field according to the main path analysis}

MP analysis was performed using the Pajek software package. ${ }^{[17]}$ The MP of the articles citation network is shown in Figure 5, and it comprises 18 articles.

Reading the MP papers, it is possible to see an evolution of the drivers and pressures for the adoption of GSCM practices. Carter et al. ${ }^{[31]}$ discussed the positive effect on firm performance as the main driver to adopt GSCM practices due to the competition with China for its entrance in the World Trade Organization (WTO) while Zhu and Sarkis ${ }^{[32]}$ suggested that globalization and economic pressures play a key role in GSCM. In Zhu et al. ${ }^{[33]}$ the authors analyzed both the market and the regulatory pressures as main drivers for the adoption of GSCM practices, but they stressed the importance of a higher awareness of these forces to be translated into a wider adoption of sustainable initiatives. González et al. ${ }^{[1]}$ analyzed the difference in the adoption of environmental practices between companies that possess a certified environmental management system (ISO 14001 or EMS) and those that do not have any such system. They observed that companies adopting a certified environmental management system usually impose to their suppliers higher environmental standards and this lead to the spread of environmental awareness along the supply chain.

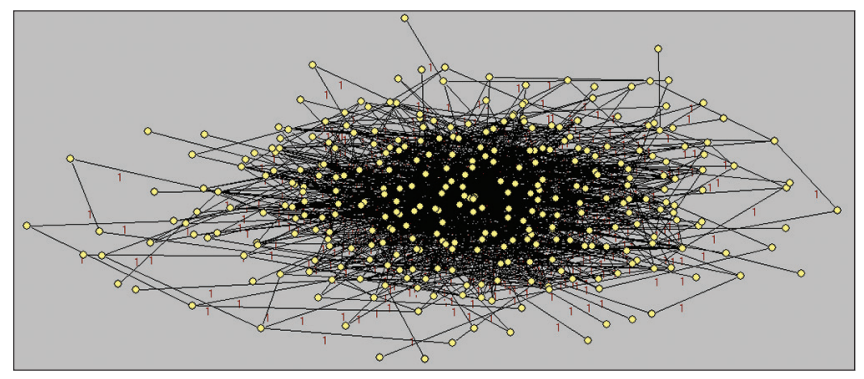

Figure 4: Main connected component of citation network of articles (337 nodes)
In Sarkis et al. ${ }^{[34]}$ the authors sought to frame the development of GSCM in some organizational theories, for example, Complexity theory, Stakeholders theory, Institutional theory, and Resource Based or Resource Dependence theory. For each theory different drivers/pressures were underlined. Moreover, the appearance of the need to frame GSCM in organizational theories is a sign of the increased importance and of a quality leap of GSCM field.

After Sarkis et al. ${ }^{[34]}$ the MP bifurcates with Wu et al. ${ }^{[35]}$ and Lai and Wong, ${ }^{[36]}$ Wu et al. ${ }^{[35]}$ investigated the relationship between GSCM drivers and GSCM practices in the Taiwan textile and apparel industry and Lai and Wong ${ }^{[3]}$ considered the manufacturing exporters in China. Wu et al. ${ }^{[3]}$ is linked to more recent papers in which some problems in the adoption of GSCM practices are highlighted. This fact represents a further step in the evolution of GSCM, and it is a clear sign of its implementation in real cases. In the study of Muduli et al. ${ }^{[37]}$ the behavioral factors for the adoption of GSCM are ranked. In Muduli et al. ${ }^{[38]}$ different barriers are considered, for example, information gap, insufficient society pressure, and poor legislation. Simpson ${ }^{[39]}$ analyzed the environmental performance improvements due to waste reduction and Mavi et al. ${ }^{[0]}$ applied a methodology to evaluate the green suppliers.

It seems that the papers of this branch of the MP have in common, rather than the findings, the quantitative methodology adopted. In fact, they all applied hierarchical ranking procedures taking into account multiple factors.

Lai and Wong ${ }^{[36]}$ identified and discussed institutional pressures as well as resources scarcity as the main drivers of green initiatives. The same did the papers linked to this node. Prajogo et al. ${ }^{[41]}$ based on institutional theory

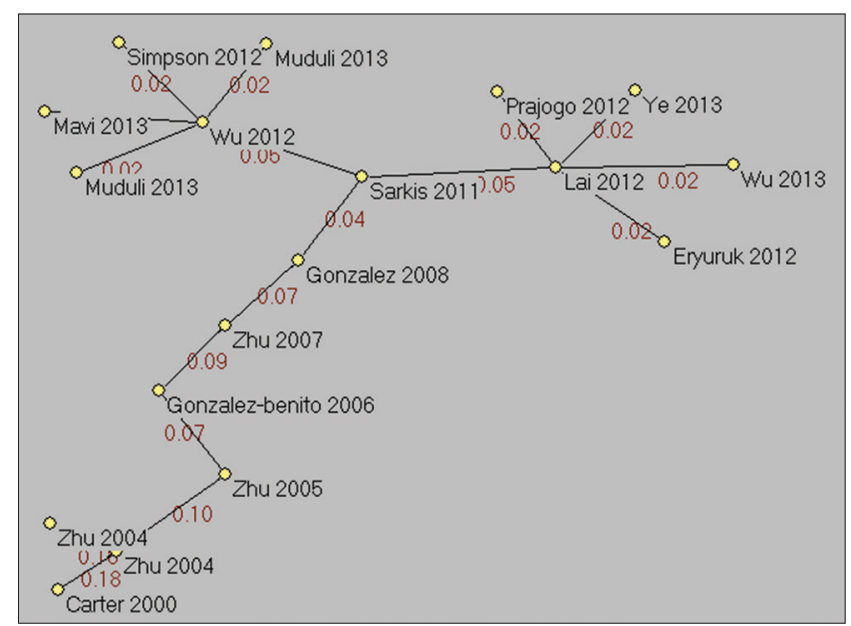

Figure 5: Main path papers 
and resource-based view (RBV), analyzed the different perceived advantages to adopt GSCM (in particular ISO 14001). Ye et al. ${ }^{[42]}$ analyzed the manager's attitude with respect to reverse logistics; $\mathrm{Wu}^{[43]}$ addressed the interchangeability in product-design and Eryuruk ${ }^{[44]}$ discussed the greenness of Textile and Clothing industry in Easter Europe with respect to product life cycle.

Summarizing, at the beginning the main drivers were economic due to the entrance of China in the WTO but the adoption of GSCM practices was not widespread, and their impact on profitability was not clear. ${ }^{[33]}$ The increase of the requests for Environmental Management Systems and the environmental standard imposed by the stakeholders lead to a spread of GSCM along the supply chain..$^{[1]}$ Sarkis et al. ${ }^{[34]}$ classify a different kind of pressures in the frame of different organizational theories and starting from this paper quantitative tools were developed for ranking barriers and advantages in the adoption of GSCM. ${ }^{[37-40]}$ and the resource base view theory became more diffused. ${ }^{[41-44]}$

Another interesting observation is that the most of the papers collected data using survey of Chinese or Taiwan enterprises. Some of them focused on India and Poland and one on Eastern Europe. The first authors of the papers are usually from one of these countries. This may be due to the fast economic development of these countries and the globalization that forces the manufacturers operating in less developed countries where the workforce is cheaper to adopt GSCM practices in order to be able to sell their product to environmentally conscious consumers all over the world.

\section{Temporal analysis of original keywords and title words}

Kleinberg's burst detection algorithm. How is it possible that only 18 papers of the MP contain the most relevant information of a set of 337 papers? We have tried to answer to this question by comparing the evolution detected in the MP with the one founded using burst detection algorithms ${ }^{[19]}$ applied to Author Keywords and Word Titles of the full network of 384 papers [Table 1].

In Figures 6 and 7, the result of burst detection algorithm applied, respectively, to Titles and original keywords after normalization is visualized using horizontal bar graph algorithm implemented in $\mathrm{Sci}^{2}$. In this visualization, the $\mathrm{X}$-axis is time, and the Y-axis is quantity. The output of this visualization consists of labeled, horizontal bars that correspond to records in the original dataset.

\section{Comparison between burst detection and main path information}

The temporal visualization of the words in Titles starts in 1992 but only in 2001 the word CHAIN bursts. This can be seen as an increased interest in the environmental practices in the supply chain. It is not a coincidence that the first paper of the MP on GSCM is Carter et al..$^{[31]}$

In 2001, China became a full member of WTO and its foreign trades increased; in 2005, the bursts of PRESSURE, PRACTICE, and CHINA words appeared. The pressure and drivers to adopt GSCM practice in China were analyzed by different MP papers during this period. ${ }^{[32,34,45]}$

In 2008, the burst of title words appeared: NETWORK, SOCIAL, RESPONS, and REVERS. Social responsibility is an ethical theory that an organization or individual entity has an obligation to act to benefit society as a whole. Social responsibility is a duty that every individual or organization must carry out in order to maintain a balance between the economy and the ecosystem. The supply chain is considered as a closed loop including the reverse part in which customers can also participate actively to implement GSCM with their respect for the environment. In 2008,

\begin{tabular}{|c|c|c|c|}
\hline Year & MP & Burst (title) & Burst (original keywords) \\
\hline $2000-2001$ & $\mathrm{GSCM}^{[31]}$ & Chain & \\
\hline 2004-2005 & The pressure and divers to adopt GSCM practices in China ${ }^{[32,33,45]}$ & $\begin{array}{l}\text { Pressure, practice, } \\
\text { China }\end{array}$ & \\
\hline 2008-2009 & 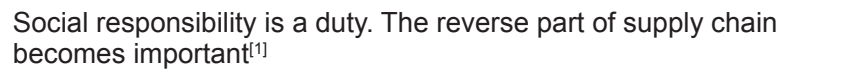 & $\begin{array}{l}\text { Network, social, } \\
\text { responsibility, reverse }\end{array}$ & $\begin{array}{l}\text { Social and reverse } \\
\text { responsibility and network }\end{array}$ \\
\hline 2011-2012 & $\begin{array}{l}\text { Organizational theory and Resource based view to protect the } \\
\text { resources that are nonsubstitutable. }{ }^{[34]} \text { The carbon production is } \\
\text { considered a measure of fossil fuel consumption }\end{array}$ & $\begin{array}{l}\text { Carbon and } \\
\text { organizational }\end{array}$ & $\begin{array}{l}\text { Organizational, emission } \\
\text { carbon and AHP }\end{array}$ \\
\hline 2013 & $\begin{array}{l}\text { Mavi et al. }{ }^{[40]} \text { proposed a methodology to evaluate suppliers using } \\
\text { fuzzy logic methods }\end{array}$ & Fuzzi, evaluate & Fuzzi and barrier \\
\hline 2013 & barriers related to the adoption of GSCM practices are analyzed ${ }^{[38]}$ & & Barriers \\
\hline
\end{tabular}

$\mathrm{MP}=$ Main path, $\mathrm{GSCM}=$ Green Supply Chain Management 
González et al. ${ }^{[1]}$ analyzed the adoption of EMS in the automotive industry. EMS is a pervasive environmental management tool, parallel to environmental audits, reverse logistics, and life cycle analysis tools in general that take into account all the aspects of the sustainability.

In 2012, the words CARBON and ORGANIZ burst and in the MP Sarkis et al. ${ }^{[34]}$ used organizational theory to categorize the literature on GSCM. One of these theories is the RBV theory. The RBV consists in identifying the firm's potential key resources and to take care and protect the resources that are nonsubstitutable. Fossil fuels are the primary sources of energy; they are nonrenewable resources because they take millions of years to form and reserves are being depleted much faster than new ones are being made. The burning of fossil fuels produces carbon dioxide $\left(\mathrm{CO}_{2}\right)$ but the natural processes can only absorb about half of that amount, so there is a net increase in the atmospheric $\mathrm{CO}_{2}$ per year. The carbon production is considered in these years a measure of fossil fuel consumption (Tseng et al., 2013). ${ }^{[46]}$

In 2013, the bursts of words FUZZY, EVALU meant that more quantitative methods have been developed to evaluate and choose suppliers. It is usually difficult to give an exact score to suppliers and some techniques based on fuzzy logic have been implemented. In the MP paper of Mavi et al. ${ }^{[40]}$ the authors proposed a methodology to evaluate suppliers using fuzzy logic methods.

In the MP in 2012-2013, the barriers related to the adoption of GSCM practices are analyzed, ${ }^{[38]}$ but in title words these aspects were not evident; this can be due to the default parameters of the burst algorithm. It is interesting

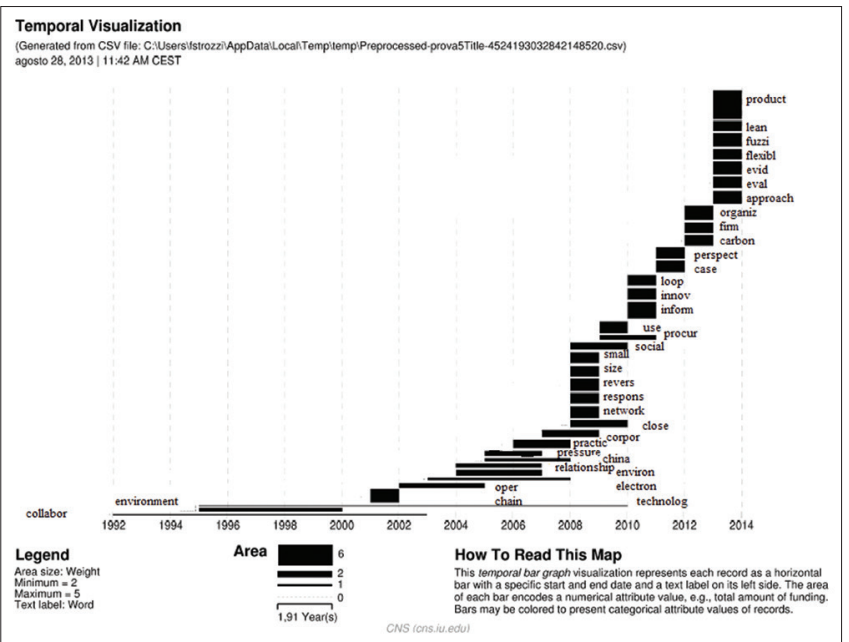

Figure 6: Burst detection algorithm applied to title words to observe that they appear in the burst of BARRIER as original keyword [Figure 7].

In original keywords [Figure 7] the burst detected in titles are confirmed. In 2008, there are the bursts of SOCIAL and REVERSE, in 2009 of RESPONS and NETWORK, in 2012 of ORGANIZ, EMISSION CARBON, and AHP, in 2013 of FUZZI and BARRIER anyway sometimes it is possible to observe a certain delay in the appearance of the concepts in Titles and in Keywords (usually, they appear in Titles before). For example, the concept of "network" bursts before in the title and after in the Keywords.

\section{Papers journals citation network}

In Figure 8, the related journals network is shown. To simplify the correspondent journal networks, it was chosen a cut value of the citations instead of the MP since in this case the evolution was not so relevant. In order to recognize the Journals more strictly connected, we have cut the links with a value lower than 9 and we have deleted the isolated nodes. The value of 9 is chosen in such a way that it is possible to easily analyze the network. The higher the cut value, the more the remaining nodes will be connected by links with heavier weights.

The layout represented in Figure 8 is obtained using Pajek software and, in particular, the Kamada-Kawai algorithm ${ }^{[47]}$ which is a force-directed algorithm that aims to reduce the edge crossing in a graph considering the link weight. This procedure is able to bring the nodes that are connected by stronger links nearer, and this visualization may help to detect correlated journals, i.e., often citing one another. A confirmation of this is given by the presence of a very

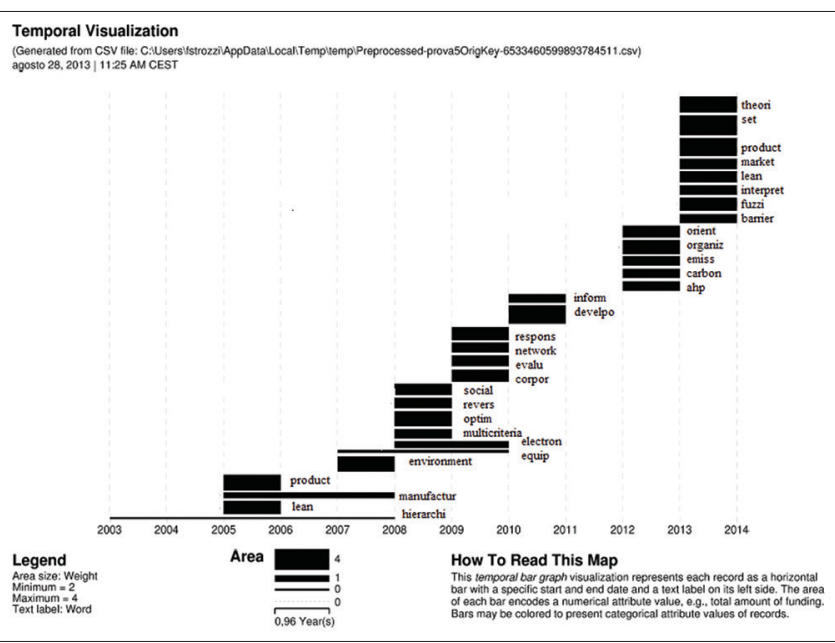

Figure 7: Burst detection algorithm applied to author keywords 


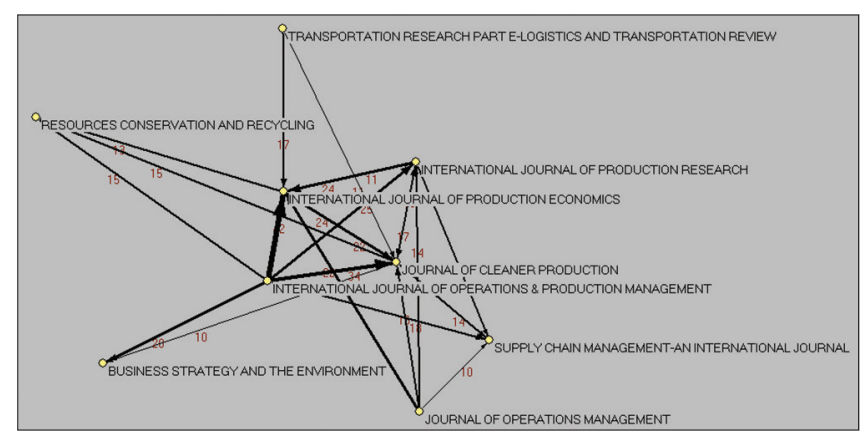

Figure 8: Journals network of articles on Green Supply Chain Management (citation weight higher than 9)

strong diamond connecting International Journal of Production Economics, Journal of Cleaner Production, International Journal of Operations and Production Research, and International Journal of Production Research. All these journals, in fact, contain the word Production in their titles.

\section{Future Research Directions Identified in Green Supply Chain Management}

To identify a framework of future developments of GSCM, we first analyzed the directions identified by the papers classified as literature reviews retrieved on Thomson Reuters Web of Science [Figure 2]. Second, we compared them with the directions identified by MP articles and burst detection algorithm. The following research directions are identified:

\section{Investigating the alignment of product/process innovation with global supply chain strategy for sustainability}

The review of Qi et al. ${ }^{[25]}$ explored different drivers for Chines firms in pursuing green process and green product innovation based on stakeholder perspective. Exportation-oriented firms should implement both process and product innovation, domestic-oriented firms may only respond to green process innovation. More research is necessary to adopt a differentiation strategy between process and product innovation. This research direction was considered in the framework of organizational stakeholder theory explained in the MP paper of Sarkis et al. ${ }^{[34]}$

\section{Investigating the social and organizational dimension of sustainability}

Seuring ${ }^{[3]}$ reviewed the modeling approaches for GSCM and identified the following future research questions: How social dimension can be integrated in the models? How the three dimensions of sustainability (environmental, social, and economic) can be interrelated? The research directions identified by Seuring ${ }^{[3]}$ can be framed in the organizational Social Network Theory presented in the MP paper of Sarkis et al. ${ }^{[34]}$

Jabbour ${ }^{[25]}$ reviewed the environmental training in organizations, i.e., the set of actions to train employees to take environmental actions. They identified many research directions between them: To compare different national contexts, to understand the characteristics of environmental training, and to analyze the relationship with other human resource practices and with particular communicational environmental practices. The research direction identified by Jabbour ${ }^{[25]}$ can be framed in the Organizational Stakeholder and Resource-Based Theories. ${ }^{[34,48]}$

\section{Investigating the environmental and social dimension of procurement}

Hejmose and Adrien-Kirbyy ${ }^{[24]}$ reviewed the research in the field of socially and environmentally responsible procurement in the first 10 years of the $21^{\text {st }}$ century, when research into social and environmental issues in buyer-supplier relationships had been intensified. ${ }^{[4,50]}$ This field became more important with the globalization and needed the development of more quantitative studies in order to identify better business strategies. The research direction identified by Hejmose and Adrien-Kirby ${ }^{[24]}$ can be framed in more than one organizational theory: Social Network Theory, Stakeholder theory, and Complexity theory. ${ }^{[34]}$

\section{Developing measures and quantitative models for sustainability}

Hassini et al. ${ }^{[2]}$ analyzed the literature on GSCM with particular attention to the aspect of developing indicators. There is a strong demand in the industry of sustainability indicators and the need to develop different indicators for different industries, more research is needed to develop composite indicators that take into account the intricacies of supply chains to help in decreasing the level of information uncertainty that companies are facing while making environmental decisions. ${ }^{[51-53]}$ The research direction identified by Hassini et al. ${ }^{[2]}$ can be framed in the organizational RBV and Resource dependence theory, since the indicators of sustainability cannot be separated from the resources considerations. Furthermore, it relates to the organizational complexity theory. 
Moreover looking to MP papers, in the branch dominated by Wu et al. ${ }^{[35]}$ there is a tendency to quantify the problems related with the adoption of $\mathrm{GSCM}^{[38]}$ which is important to develop better sustainability indicators. In the branch dominated by Lai and Wong, ${ }^{[36]}$ Prajogo et al. ${ }^{[41]}$ analyzed the relationship between the adoption of ISO 14001 and the companies' performance. This research direction is confirmed by the publication of a recent literature review of Nuss et al..$^{[54]}$ where a classification scheme for planning problems in reverse logistics was developed.

\section{Integrating lean approaches into supply chain sustainability}

This direction is not present in the previous literature reviews on the GSCM. Looking to burst detection, [Figure 6] the word lean bursts recently both in titles and in Author Keywords and this suggests a new research tendency, i.e., to explore more in detail the application of the lean philosophy and supply chain management practices to the framework of sustainability, as highlighted by some recent papers. ${ }^{[5-58]}$

\section{Pros and Cons of the Adopted Methodology}

There are in the literature some criticisms about the adopted methodology. Considering only citations may be not completely informative about the influence that a research has on the future ones. ${ }^{[59]}$ Furthermore, the citations are retrieved and downloaded from databases such as Scopus, Web of Science, Google Scholar, etc., that are limited to a fraction of the scientific publications. Another problem can be what is called the Matthiew effect, i.e., the rich get richer; in fact, people tend to cite already well-cited works by well-known researchers, either because that is what they have read or because they are appealing to the authority of the better known or both.

While, it is risky to evaluate research based only on citations, on the other hand, it is increasingly essential to provide researchers with blind tools, enabling fast literature reviews in increasingly specialized and different fields. From our point of view, it is important to continue to work using citations but also, at the same time, try to develop measures and weights of the citations that eliminate as much as possible the current problems and retain the ability to identify quickly the most important works in a field using the informatics tools available nowadays.

Taking into account the aforementioned observations and the possible incompleteness of the database, it could be possible that in this literature review we have overlooked some important works since they were not sufficiently cited within the database itself. Notwithstanding these limitations, we believe that this analysis was able to identify the evolution of GSCM, its main areas of research and to suggest promising future research directions.

\section{CONCLUSIONS}

GSCM development is studied using CNA and burst detection algorithm to understand the evolution of the field. The proposed methodology can be applied to different research areas, and it is very useful when fields are fast evolving, and it is necessary to have a quick overview of the themes on which most of the researches are focused.

The MP reveals that GSCM initially focused on issues related to quality management and economic performances has more recently embraced the social dimension of sustainability and the need for quantitative models able to support the integration of sustainable objectives both within the organizations and among the partners of the same supply chain. One of the most important nodes of the MP is Sarkis et al. ${ }^{[3]}$ in which the authors combine different drivers with different institutional theories. After Sarkis et al. ${ }^{[34]}$ the MP bifurcates into two branches: One dominated by Wu et al. ${ }^{[3]}$ including papers also addressing the negative impacts stemming from the adoption of GSCM practices, while in the other, dominated by Lai and Wong, ${ }^{[36]}$ the authors analyzed the relationship between the drivers and the institutional theories with particular emphasis on those related to the scarcity of resources. This is not surprising since the rapid economic development of China and Eastern countries led to the increase of environmental pollution and resource scarcity which represents a serious limit to the idea of economic growth.

The same evolution of drivers appears from the burst detection in Title Words and in Authors Keywords. In 2001, China became a full member of WTO and the exportations increased. It had to face to consumers pressure for a more sustainable production (Pressure in burst detection in Title Words) and later on, institutional pressures to maintain a balance between economy and ecosystem (carbon emission appeared in burst detection figure) and to manage the resource scarcity.

Regarding the future research directions, we have first analyzed the directions proposed by previous literature reviews on GSCM and we checked if the MP papers 
confirmed these directions. We have then explored the most recent MP papers in which new directions are suggested and analyzed the results of the MP analysis and the burst detection algorithm. In this way, we were able to identify new research directions that were not included in previous literature reviews, which may further support the development of GSCM. Furthermore, some managerial insights can be derived on how to create a green supply chain: By developing key performance indicators of sustainability; by integrating the economic, environmental, and social dimensions of sustainability, internally within the organization, and externally among the supply chain partners; and by exploring the application of lean philosophy to the framework of sustainability.

The analysis of the papers citation network alone due to the above-described limitations, may not be able to identify all the most influential papers. The tool of burst detection can be used to confirm and sometimes expand the results of the papers citation network. In our opinion, a literature review based on a systematic processing and management of the information contained in scholar database is very important, especially to analyze a fast evolving research field to be able to understand the key themes and quickly build a research directions landscape.

\section{Financial Support and Sponsorship}

Nil.

\section{Conflicts of Interest}

There are no conflicts of interest.

\section{REFERENCES}

1. González P, Sarkis J, Adenso-Díaz B. Environmental management system certification and its influence on corporate practices Evidence from the automotive industry. Int J Oper Prod Manage 2008;28:1021-41.

2. Hassini E, Surti C, Searcy C. A literature review and a case study of sustainable supply chains with a focus on metrics. Int J Prod Econ 2012;140:69-82.

3. Seuring S. A review of modeling approaches for sustainable supply chain management. Decis Support Syst 2013;54:1513-20.

4. Ashby A, Leat M, Hudson-Smith M. Making connections: A review of supply chain management and sustainability literature. Supply Chain Manage Int J 2012;17:497-516.

5. Srivastava SK. Green supply-chain management: A state-of-the-art literature review. Int J Manage Rev 2007;9:53-80.

6. Wilding R, Wagner B. Building theory in supply chain management through systematic reviews of the literature. Supply Chain Manage Int J 2014;19:ISS 5/6.

7. Otte E, Rousseau R. Social network analysis: A powerful strategy, also for the information sciences. J Inf Sci 2002;28:441-53.

8. Ma N, Guan J, Zhao Y. Bringing page rank to the citation analysis. Inf Process Manage 2008;44:800-10.

9. Thelwall M, Vann K, Fairclough R. Web issue analysis: An integrated water resource management case study. J Am Soc Inf Sci Technol 2006;57:1303-14.

10. Kajikawa $\mathrm{Y}$, Ohno J, Takeda $\mathrm{Y}$, Matsushima K, Komiyama H. Creating an academic landscape of sustainability science: An analysis of the citation network. Sustain Sci 2007;2:221-31.

11. Nakamura H, Suzuki S. Structure and Dynamics of Knowledge in Supply Chain Research, $19^{\text {th }}$ International Conference on Management of Technology, IAMOT 2010 Proceedings; 2010.

12. Colicchia C, Strozzi F. Supply chain risk management: A new methodology for a systematic literature review. Supply Chain Manage Int J 2012;17:403-18.

13. Hummon NP, Doreian P. Connectivity in a citation network: The development of DNA theory. Soc Netw 1989;11:39-63.

14. Strozzi F, Colicchia C. Literature review on complex network methods applied to measure robustness in supply chain design. Liuc Papers n. 249, Serie Metodi Quantitativi 20, luglio 2012. ISSN: $1722-4667$

15. Strozzi F, Colicchia C. Sorrenti A.Literature review on environmental indicators for supply chains using "Systematic Literature Network Analysis". LIUC Paper n. 267, Serie Metodi Quantitativi, luglio 2013, ISSN:1722-4667.

16. Newbert SL. Empirical research on the resource based view of the firm: An assessment and suggestions for future research. Strateg Manage J 2007;28:121-46.

17. De Nooy W, Mrvar A, Batagelj V. Exploratory Social Network Analysis with Pajek. New York:Cambridge University Press; 2005.

18. Lucio-Arias D, Leydesdorff L. Main path analysis and path-dependent transitions in HistCite based histograms. J Am Soc Inf Sci Technol 2008;59:1948-62.

19. Kleinberg J. Bursty and Hierarchical Structure in Streams, Proceedings $8^{\text {th }}$ ACM SIGKDD International Conference on Knowledge Discovery and Data Mining; 2002.

20. Fu, H, Wang M, Ho Y. Mapping of drinking water research: A bibliometric analysis of research output during 1992-2011. Sci Total Environ 2013;443:757-65.

21. Corbett CJ, Klassen RD. Extending the horizons: Environmental excellence as key to improving operations. Manuf Serv Oper Manag 2006;8:5-22.

22. Seuring $S$, Muller M. From a literature review to a conceptual framework for sustainable supply chain management. J Clean Prod 2008;16:1699-710.

23. Hoejmose SU, Adrien-Kirby AJ. Socially and environmentally responsible procurement: A literature review and future research agenda of a managerial issue in the $21^{\text {st }}$ century. J Purch Supply Manage 2012;18:232-42.

24. Jabbour CJ. Environmental training in organisations: From a literature review to a framework for future research. Resour Conserv Recycling 2013;74:144-55.

25. Qi G, Zeng S, Tam C, Yin H, Zou H. Stakeholders' influences on corporate green innovation strategy: A case study of manufacturing firms in China. Corp Soc Responsib Environ Manage 2013;20:1-14.

26. Beškovnik B, Jakomin L. Challenges of green logistics in Southest Europe. Promet Traffic Traffico 2010;22:147-55.

27. Eagan PD, Kaiser B. Can environmental purchasing reduce mercury in U.S. health care? Environ Health Perspect 2002;110:847-51.

28. Lam JS, Gu Y. Port hinterland intermodal container flow optimisation with green concerns: A literature review and research agenda. Int J Shipping Transp Logist 2013;5:257-81.

29. Clark HA, Snedeker SM. Ochratoxin a: Its cancer risk and potential for exposure. J Toxicol Environ Health B Crit Rev 2006;9:265-96.

30. Ellram LM, Tate W, Carter CR. Applying 3DCE to environmentally responsible manufacturing practices. J Clean Prod 2008;16:1620-31. 
31. Carter CR, Rahul K, Curtis MG. Environmental purchasing and firm performance: An empirical investigation. Transp Res Part E 2000;36:219-28.

32. Zhu Q, Sarkis J. Relationships between operational practices and performance among early adopters of green supply chain management practices in Chinese manufacturing enterprises. J Oper Manage 2004;22:265-89.

33. Zhu Q, Sarkis J, Geng Y. Green supply chain management in China: Pressures, practices and performance. Int J Oper Prod Manage 2005;25:449-68.

34. Sarkis J, Zhu Q, Lai K. An organizational theoretic review of green supply chain management literature. Int J Prod Econ 2011;130:1-15.

35. Wu G, Ding J, Chen P. The effects of GSCM drivers and institutional pressures on GSCM practices in Taiwan's textile and apparel industry. Int J Prod Econ 2012;135:618-36.

36. Lai K, Wong CW. Green logistics management and performance: Some empirical evidence from Chinese manufacturing exporters. Omega 2012;40:267-82.

37. Muduli K, Govindan K, Akhilesh B, Devika K, Yong G. Role of behavioral factors in green supply chain management implementation in Indian mining industries. Resour Conserv Recycling 2013;76:50-60.

38. Muduli K, Kannan G, Akhilesh B, Yong G. Barriers to green supply chain management in Indian mining industries: A graph theoretic approach. J Clean Prod 2013;47:335-44.

39. Simpson D. Institutional pressure and waste reduction: The role of investments in waste reduction resources. Int $\mathrm{J}$ Prod Econ 2012;139:330-9.

40. Mavi RK, Kazemi S, Najafabadi AF, Mousaabadi HB. Identification and assessment of logistical factors to evaluate a green supplier using the fuzzy logic DEMATEL method. Pol J Environ Stud 2013;22:445-55.

41. Prajogo D, Tang AK, Lai K. Do firms get what they want from ISO 14001 adoption? An Australian perspective. J Clean Prod 2012;33:117-26.

42. Ye F, Zhao X, Prahinski C, Li Y. The impact of institutional pressures, top managers' posture and reverse logistics on performance-evidence from China. Int J Prod Econ 2013;143:132-43.

43. Wu C. OEM product design in a price competition with remanufactured product. Manage Sci Environ Issues 2013;41:287-98.

44. Eryuruk SH.Greening of the textile and clothing industry. Fibres Text East Eur 2012;95:22-7.
45. Zhu Q, Sarkis J. The moderating effects of institutional pressures on emergent green supply chain practices and performance. Int J Prod Res 2007;45:4333-55.

46. Tseng ML, Chiu SF, Tan RR, Siriban-Manalang AB. Sustainable consumption and production for Asia: Sustainability through green design and practice. J Clean Prod 2013;40:1-5.

47. Kamada T, Kawai S. An algorithm for drawing general undirected graphs. Inf Process Lett 1998;31:7-15.

48. Adams S, Bessant J, Phelps R. Innovation management measurement: A review. Int J Manage Rev 2006;8:21-47.

49. Hartmann J, Moeller S. Chain liability in multitier supply chains? Responsibility attributions for unsustainable supplier behaviour. J Oper Manage 2014;32:281-94.

50. Tachizawa EM, Wong CY. Towards a theory of multi-tier sustainable supply chains: A systematic literature review. Supply Chain Manage Int J 2014;19:5-6.

51. Grosvold J, Hoejmose SU, Roehrich JK. Squaring the circle: Management, measurement and performance of sustainability in supply chains. Supply Chain Manage Int J 2014;19:292-305.

52. Varsei M, Soosay C, Fahimnia B, Sarkis J. Framing sustainability performance of supply chains with multidimensional indicators. Supply Chain Manage Int J 2014;19:242-57.

53. Wu Z, Pagell M. Balancing priorities: Decision-making in sustainable supply chain management. J Oper Manage 2011;29:577-90.

54. Nuss $C$, Sahamie R, Stindt D. The reverse supply chain planning matrix: A classification scheme for planning problems in reverse logistics. Int J Manage Rev 2014;17:413-36.

55. Azevedo SG, Carvalho H, Duarte S, Cruz-Machado V. Influence of green and lean upstream supply chain management practices on business sustainability. IEEE Trans Eng Manage 2012;59:753-65.

56. Dües CM, Tan KH, Lim M. Green as the new Lean: How to use lean practices as a catalyst to greening your supply chain. J Clean Prod 2013;40:93-100.

57. Hajmohammad S, Vachon S, Klassen RD, Gavronski I. Lean management and supply management: Their role in green practices and performance. J Clean Prod 2013;39:312-20.

58. Yang MG, Hong $P$, Modi SB. Impact of lean manufacturing and environmental management on business performance: An empirical study of manufacturing firms. Int J Prod Econ 2011;129:251-61.

59. Shema H. What's Wrong with Citation Analysis? 2013. Available from: http://www.blogs.scientificamerican.com/information-culture /2013/01/01/whats-wrong-with-citation-analysis/. [Last accessed on 2015 Jan 1]. 